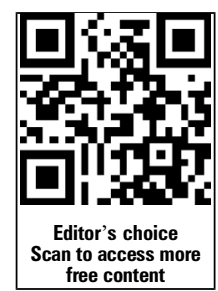

1 Department of Sports Medicine, Norwegian Research Center for Active Rehabilitation (NAR), Norwegian School of Sport Sciences, Oslo, Norway ${ }^{2}$ Department of Physical Therapy, College of Health Sciences, University of Delaware, Newark, Delaware, USA

${ }^{3}$ Oslo Sports Trauma Research Center, Norwegian School of Sport Sciences, Oslo, Norway ${ }^{4}$ Department of Orthopaedics, Oslo University Hospital, Oslo, Norway

\section{Correspondence to} Dr Hege Grindem, Nimi/NAR, Pb. 3848 Ullevaal Stadion, 0805 Oslo, Norway; hege. grindem@nih.no

Accepted 18 April 2016 Published Online First 9 May 2016

\title{
Simple decision rules can reduce reinjury risk by 84\% after ACL reconstruction: the Delaware-Oslo ACL cohort study
}

Hege Grindem, ${ }^{1}$ Lynn Snyder-Mackler, ${ }^{2}$ Håvard Moksnes, ${ }^{3}$ Lars Engebretsen, ${ }^{3,4}$ May Arna Risberg ${ }^{1,4}$

ABSTRACT
Background Knee reinjury after $A C L$ reconstruction is common and increases the risk of osteoarthritis. There is sparse evidence to guide return to sport (RTS) decisions in this population.

Objectives To assess the relationship between knee reinjury after $A C L$ reconstruction and (1) return to level I sports, (2) timing of RTS and (3) knee function prior to return.

Methods 106 patients who participated in pivoting sports participated in this prospective 2-year cohort study. Sports participation and knee reinjury were recorded monthly. Knee function was assessed with the Knee Outcome Survey-Activities of Daily Living Scale, global rating scale of function, and quadriceps strength and hop test symmetry. Pass RTS criteria were defined as scores $>90$ on all tests, failure as failing any.

Results Patients who returned to level I sports had a $4.32(p=0.048)$ times higher reinjury rate than those who did not. The reinjury rate was significantly reduced by $51 \%$ for each month RTS was delayed until 9 months after surgery, after which no further risk reduction was observed. $38.2 \%$ of those who failed RTS criteria suffered reinjuries versus $5.6 \%$ of those who passed (HR $0.16, p=0.075)$. More symmetrical quadriceps strength prior to return significantly reduced the knee reinjury rate.

Conclusions Returning to level I sports after $\mathrm{ACL}$ reconstruction leads to a more than 4-fold increase in reinjury rates over 2 years. RTS 9 months or later after surgery and more symmetrical quadriceps strength prior to return substantially reduce the reinjury rate.

\section{INTRODUCTION}

In total, $250000 \mathrm{ACL}$ injuries are estimated to occur annually in the USA. ${ }^{1}$ The short-term and long-term consequences include muscle weakness, functional deficits, lower sports participation, increased risk of knee reinjury and knee osteoarthritis (OA). ${ }^{2-5}$ Up to $30 \%$ of young active patients who undergo reconstruction suffer a second ACL rupture in the first few years after surgery, ${ }^{3} 6$ leading to poorer health-related quality of life. ${ }^{7}$ The most devastating outcome, however, is the significantly increased rate of knee $\mathrm{OA}$ in those ACL-injured individuals who also sustain a meniscus injury. Within 5 years, $50 \%$ of patients may undergo meniscus surgery, ${ }^{8}$ increasing their prognosis of post-traumatic knee OA from $0-13 \%$ to $21-48 \%{ }^{4}$ We can reduce this high rate of knee OA through prevention of secondary meniscus injuries. In the USA alone, halving the OA rate after ACL injury could lead to $\$ 1.1$ billion in cost savings annually. ${ }^{9}$

Intent to return to level I (jumping, pivoting and hard cutting) sports ${ }^{10-12}$ is the main reason why a patient with an ACL rupture undergoes ACL reconstruction. ${ }^{5}$ Younger age and participation in pivoting sports are also unfortunately consistent predictors of another ACL rupture after ACL reconstruction. ${ }^{13-17}$ Activity restrictions based on postsurgical time (a surrogate for biological healing) and functional status (assessed with test batteries) have been advocated to enable the safest possible return to sport (RTS). ${ }^{18} 19$ There is currently no clear evidence to guide whether participation in level I sports should be delayed or what level of function the patient should achieve prior to returning to level I sports. ${ }^{20}$

The aims of this study were therefore to assess if the 2-year risk of a knee reinjury after ACL reconstruction was associated with (1) return to level I sports, (2) timing of return to level I sports and (3) knee function prior to return to level I sport.

\section{MATERIAL AND METHODS \\ Participants}

This cohort consists of the ACL-injured patients in the Norwegian arm $(n=150)$ of the Delaware-Oslo ACL Cohort Study $(n=300)$ who underwent ACL reconstruction $(n=106) .^{5}$ Patients were consecutively screened for inclusion at the Norwegian Sports Medicine Clinic between 2007 and 2011. We included patients who had sustained a unilateral ACL rupture within 3 months of enrolment (verified by MRI and $\geq 3 \mathrm{~mm}$ side-to-side difference in anterior laxity measured by KT- $1000^{21}$ ). Other inclusion criteria were age between 13 and 60 years and preinjury participation in level I or II sports ${ }^{10}$ at least twice weekly. Patients were excluded if they had current or previous injury to the contralateral knee, previous knee injury on the index knee, or concomitant grade III knee ligament injury, fracture or full-thickness cartilage defects. Patients with meniscus injuries were excluded only if they had pain or effusion during plyometric activities that had not resolved 3 months from injury. Approval from the Regional Committee for Medical Research Ethics was obtained, and written informed consent was acquired, prior to inclusion.

\section{Treatment algorithm}

All patients underwent our previously published preoperative rehabilitation programme. ${ }^{22}$ Further treatment (surgery or continued rehabilitation) was 
decided after this 5-week programme. The ACL reconstruction was performed in one of seven different hospitals, using bonepatellar tendon-bone (BPTB) or a hamstrings autograft. The postoperative rehabilitation was individually tailored on the basis of concomitant surgery, graft choice and function. Rehabilitation consisted of three phases: the acute phase where the aims were to eliminate effusion and range of motion (ROM) deficits and minimise muscle atrophy. The rehabilitation phase where the aims were to regain neuromuscular control of terminal knee extension in weight-bearing positions and to regain $\geq 80 \%$ muscle strength and hop performance. The last phase, the RTS phase, aimed at regaining $\geq 90 \%$ muscle strength and hop performance, while transitioning to sport through sport-specific drills and gradual participation. Patients were advised against full participation in level I sports if they had not regained $>90 \%$ quadriceps and hamstring strength and hopping performance compared with the uninjured leg.

\section{Data collection}

Starting the first month after ACL reconstruction, sports participation data were collected monthly using an online activity survey. ${ }^{11}$ Patients reported which sports they participated in by ticking a box for the respective sport. Each month, one reminder was automatically sent out to patients who had not responded after 1 week. The online activity survey has excellent test-retest reliability ( $\kappa=0.92$ for level I sports participation). ${ }^{11}$ Knee reinjuries with an acute onset were recorded through the online survey and at clinical follow-ups at 6 months, 1 year and 2 years after reconstruction. The injuries were diagnosed according to the standard practice at our clinic. Of 24 reinjured patients, 2 were diagnosed after clinical examination, 10 after clinical examination and MRI, 5 after clinical examination and arthroscopic surgery, and 7 after clinical examination, MRI and arthroscopic surgery.

The comprehensive RTS test battery ${ }^{19} 2324$ investigated in this study consisted of isokinetic quadriceps strength testing, four single-legged hop tests and two self-report outcomes. ${ }^{23} 24$ These data were collected at baseline (mean 2.1 \pm 0.6 months after injury) and at 6 and 12 months after surgery. Isokinetic concentric quadriceps strength was measured at $60 \%$ with an electromechanical dynamometer (Biodex6000, Biodex Medical Systems, Shirley, New York, USA). Four submaximal practice trials were followed by $1 \mathrm{~min}$ rest before five maximum effort repetitions were recorded. After strength testing, four hop tests were performed in the following order: single hop for distance, crossover hop for distance, triple hop for distance and $6 \mathrm{~m}$ timed hop. ${ }^{25} 26$ All patients performed one practice trial hop and then two hops were recorded. The uninvolved leg was always tested first. After the hop testing, patients completed the Knee Outcome Survey-Activities of Daily Living Scale $(\text { KOS-ADLS })^{27}$ and a global rating scale (GRS) of perceived function. ${ }^{23}$ The KOS-ADLS is a 14 -item self-reported assessment of symptoms and function in activities of daily living, scored from 0 (worst) to 100 (best). The GRS asks the patient to rate current knee function on a scale from 0 (not able to perform any activity) to 100 (level of function prior to the knee injury).

\section{Data management and statistical analysis}

Return to level I sport was defined as any reported participation in handball, football, basketball or floorball, regardless of training/match participation or level of competition. The first recorded participation in level I sports was reported in months after surgery.
We extracted data on knee function from the 6-month follow-up for those who returned to level I sports 5-11 months after surgery $(n=49)$ and from the 12-month follow-up for those who returned $12-23$ months after surgery $(n=20)$. The limb symmetry indexes (LSIs) of the peak quadriceps torque (highest achieved value) and hop test distance/time were calculated by involved/uninvolved $\times 100$, except for the $6 \mathrm{~m}$ timed hop test which was calculated by uninvolved/involved $\times 100$. Patients were classified as having passed RTS criteria if they scored $>90$ on all seven variables. Patients who returned to level I sport $<5$ months after surgery $(n=4)$ were a priori classified as not having passed RTS criteria. ${ }^{23} 24$

A Cox proportional hazards regression model with months after surgery as the time variable was used to assess the reinjury rate in patients who participated in level I sports after surgery versus those who did not. Cox regression models were also used to assess the association between knee reinjury and time of return, and knee function prior to return to level I sports. Time 0 was defined as the first month of level I sports participation to limit bias from more sports exposure in patients who returned early to level I sports. The independent variables were months from surgery to RTS, passing/failing RTS criteria and continuous LSIs of the individual RTS variables. Separate results were reported for those who returned before and after 9 months after surgery, as the assumption of proportionality was violated in the analysis of time of return. All analyses were adjusted for age. Two-sided $\mathrm{p}$ values $\leq 0.05$ were considered statistically significant.

\section{RESULTS}

From the original 106 patients who underwent ACL reconstruction, $100(94.3 \%)$ had data on sports participation and knee reinjuries ( 1 withdrew from the study, 5 did not respond to the online activity survey). The monthly data on sports participation and reinjuries were $92.9 \%$ complete for the 100 patients $(2230$ reports in total). Descriptive characteristics of the cohort can be seen in table 1.

In total, 74 of the 83 patients who previously participated in level I sports returned to level I sports within 2 years of ACL reconstruction. None of the 17 who did not participate in level I sport before injury participated in level I sports after surgery. The mean number of months participating in level I sports was $8.1 \pm 5.7$ over the two postoperative years. The time of return to level I sports varied from 3 to 23 months after surgery, with a median of 8 months after surgery.

In total, 69 of the $74(93.2 \%)$ patients who participated in level I sports underwent functional testing prior to RTS. One patient did not attend any of the follow-ups. Four patients returned to sport fewer than 5 months after surgery. All four of these patients suffered a knee reinjury within 2 months of return. The mean time from functional testing to return to level I sport was $2.3 \pm 2.4$ months. Of the 49 patients who returned to level I sports 5-11 months after surgery, 7 (14.3\%) had passed the RTS criteria at the 6-month follow-up test. Eleven of the 20 patients (55.0\%) who returned to level I sport 12-23 months after surgery had passed the RTS criteria at the 12-month follow-up. In total, 18 of the 74 patients $(24.3 \%)$ were classified as having passed the functional RTS criteria prior to RTS.

Twenty-four (24.0\%) patients sustained 28 knee reinjuries, including 8 ACL graft ruptures and 8 medial meniscus injuries (table 2). The reinjuries occurred from the 3 rd to the 22 nd postoperative month, with a median of 13 months after surgery. The time between returning to level I sports and sustaining a knee reinjury varied from $<1$ month to 16 months, with $45.5 \%$ of the reinjuries sustained within 2 months of RTS. In the 26 
Table 1 Characteristics of the ACL reconstructed patients $(n=100)$

\begin{tabular}{|c|c|}
\hline Sex, men/women (\% men) & $46 / 54(46.0)$ \\
\hline Age, mean \pm SD & $24.3 \pm 7.3$ \\
\hline Preinjury participation in level I sports, n (\%) & $83(83.0)$ \\
\hline Handball* & $30(30.0)$ \\
\hline Football* & $53(53.0)$ \\
\hline Basketball* & $6(6.0)$ \\
\hline Floorball* & $11(11.0)$ \\
\hline Months from injury to surgery, median (minimum-maximum) & $4.8(1.6-25.4)$ \\
\hline \multicolumn{2}{|l|}{$\mathrm{ACL}$ graft, $\mathrm{n}(\%)$} \\
\hline BPTB & $33(33.0)$ \\
\hline Hamstring & $67(67.0)$ \\
\hline \multicolumn{2}{|l|}{ Baseline concomitant injuries, $\mathrm{n}(\%)$} \\
\hline Medial meniscus injury & $26(26.0)$ \\
\hline Lateral meniscus injury & $20(20.0)$ \\
\hline Medial cartilage injury & $3(3.0)$ \\
\hline Lateral cartilage injury & $9(9.0)$ \\
\hline MCL injury grade I-II & $30(30.0)$ \\
\hline LCL injury grade I-II & $1(1.0)$ \\
\hline Popliteus injury & $2(2.0)$ \\
\hline \multicolumn{2}{|l|}{ Baseline knee function, mean $\pm S D$} \\
\hline Quadriceps strength, LSI & $89.2 \pm 10.2$ \\
\hline Single hop for distance, LSI & $91.2 \pm 10.4$ \\
\hline Triple crossover hop, LSI & $92.9 \pm 9.3$ \\
\hline Triple hop, LSI & $91.3 \pm 8.3$ \\
\hline $6 \mathrm{~m}$ timed hop, LSI & $94.6 \pm 8.3$ \\
\hline KOS-ADLS & $82.4 \pm 9.6$ \\
\hline Global rating scale & $79.3 \pm 12.8$ \\
\hline \multicolumn{2}{|c|}{$\begin{array}{l}\text { Baseline: At enrolment in the study and prior to ACL reconstruction, mean } 2.1 \\
\text { (SD 0.6) months from injury. } \\
\text { Concomitant injuries were diagnosed by MRI. } \\
\text { *Some participated in multiple level I sports. } \\
\text { BPTB, bone-patellar tendon-bone; KOS-ADLS, Knee Outcome Survey-Activities of } \\
\text { Daily Living Scale; LCL, lateral collateral ligament; LSI, limb symmetry index; MCL, } \\
\text { medial collateral ligament. }\end{array}$} \\
\hline
\end{tabular}

patients who did not return to level I sports, two reported a knee reinjury $(7.7 \%)$. The 2-year reinjury risk in patients who returned to level I sports after surgery was $29.7 \%$ (22 of 74 ). After adjusting for age, patients who participated in level I sports after ACL reconstruction had a 4.32 (95\% CI 1.01 to $18.40, \mathrm{p}=0.048$ ) times higher reinjury rate than those who participated in lower level sports (figure 1).

During the first 9 months after surgery, a later RTS was significantly associated with a lower reinjury rate. For every 1 month delay in RTS, the reinjury rate was reduced by $51 \%$ (table 3). In patients who returned between 9 and 23 months after surgery, time to return was not significantly associated with knee reinjury. Patients who participated in level I sports earlier than 9 months after surgery sustained $39.5 \%$ reinjuries (15 of 38), compared with $19.4 \%$ knee reinjuries (7 of 36) in those who returned to level I sports later than 9 months after surgery.

Of the 55 patients who failed RTS criteria, 21 (38.2\%) suffered knee reinjuries (figure 2). Only 1 of the 18 patients (5.6\%) who passed RTS criteria suffered a knee reinjury. Patients who passed the RTS criteria showed a not statistically significant $84 \%$ lower reinjury rate (HR 0.16 (95\% CI 0.02 to $1.20, \mathrm{p}=0.075)$ ). Of the individual components in the RTS test battery, quadriceps strength deficit prior to return to level I sport was a significant predictor of a knee reinjury, with a 3\% reduced reinjury rate for every one percentage point increase in strength symmetry (table 3). Fifteen of the 45 patients $(33.3 \%)$ who returned to level I sport with quadriceps LSI $<90 \%$ suffered reinjuries, versus three $(12.5 \%)$ reinjuries
Table 2 Knee reinjuries over 2 years in ACL reconstructed patients

\begin{tabular}{ll}
\hline Index knee & $\mathrm{n}(\%)$ \\
ACL graft rupture & $8(8.0)$ \\
Medial meniscus injury & $8(8.0)$ \\
Lateral meniscus injury & $2(2.0)$ \\
Medial cartilage injury & $1(1.0)$ \\
Lateral cartilage injury & $1(1.0)$ \\
Patellofemoral cartilage injury & $2(2.0)$ \\
Medial collateral ligament injury & $1(1.0)$ \\
Patella subluxation & $1(1.0)$ \\
Contralateral knee & \\
ACL rupture & $2(2.0)$ \\
Lateral meniscus injury & $1(1.0)$ \\
Medial collateral ligament injury & $1(1.0)$ \\
\hline $\mathrm{n}$ (\%). & \\
Four patients had two reinjuries (same trauma).
\end{tabular}

in the 24 patients who had quadriceps LSI $>90 \%$ prior to return.

\section{DISCUSSION}

This 2-year prospective study showed that the knee reinjury rate was over four times higher in ACL reconstructed patients who returned to level I sports after surgery. Furthermore, returning to sport earlier after surgery and having asymmetrical quadriceps strength prior to return increased the risk of knee reinjury.

Our study is the first to evaluate the risk of all acute knee reinjuries in those who return to high level pivoting sports. Meniscus injury was the most frequent knee reinjury, a significant factor for development of OA. ${ }^{28}$ Reducing the risk of secondary injuries is therefore of uttermost importance. The age and sex distribution of our patient sample is similar to patients in the Scandinavian ACL registries ${ }^{29}$ and the ACL reinjury rate seems to be generally consistent with previous studies in young, active adults, ${ }^{30} 31$ yet lower than that of high school athletes. ${ }^{3}$

Previous studies on time to sports return and the risk of contralateral ACL rupture or ACL graft rupture have shown conflicting evidence. ${ }^{3} 1631$ Different sports place different

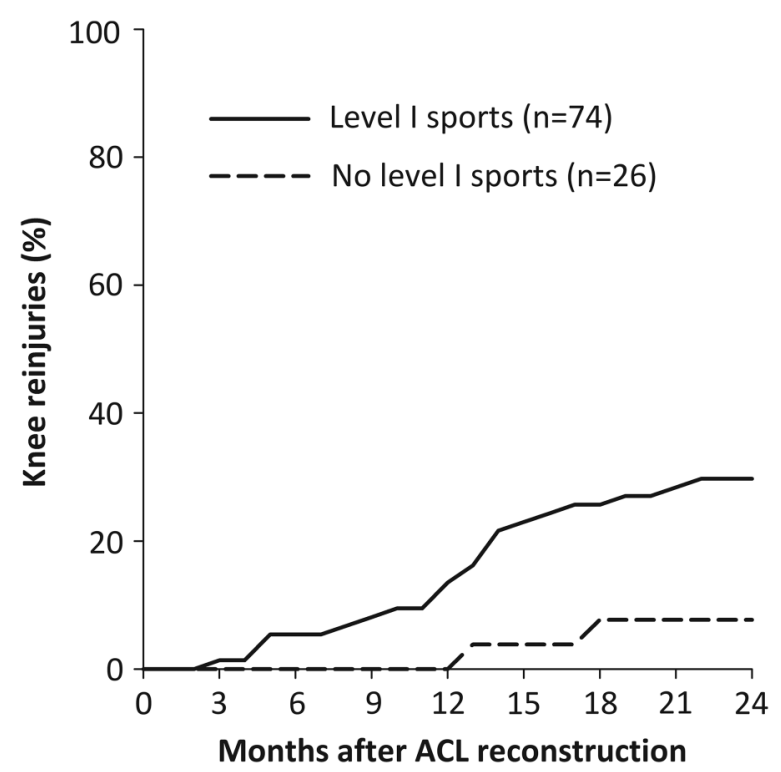

Figure 1 Knee reinjuries after $A C L$ reconstruction in those who participated in level I sports and those who did not. 
Table 3 Factors associated with knee reinjury in patients who returned to level I sport after ACL reconstruction $(n=74)$

\begin{tabular}{|c|c|c|c|c|c|}
\hline & $\mathbf{n}$ & No reinjury & $\mathbf{n}$ & Reinjury & Adjusted HR $(95 \% \mathrm{CI})$, p value \\
\hline \multicolumn{6}{|l|}{ All patients } \\
\hline Return to level I sports, months from surgery & 52 & $10.7 \pm 4.3$ & 22 & $7.2 \pm 2.7$ & \\
\hline Passed RTS criteria, n (\%) & 51 & $17(33.3)$ & 22 & $1(4.5)$ & $0.16(0.02$ to 1.20$), 0.08$ \\
\hline Quadriceps strength, LSI & 51 & $84.4 \pm 15.2$ & 18 & $75.0 \pm 16.7$ & 0.97 (0.94 to 0.99$), 0.03$ \\
\hline Single hop for distance, LSI & 48 & $89.4 \pm 13.0$ & 17 & $91.0 \pm 11.7$ & 1.01 (0.96 to 1.05 ), 0.77 \\
\hline Triple crossover hop, LSI & 47 & $90.7 \pm 11.8$ & 16 & $93.8 \pm 8.5$ & $1.04(0.98$ to 1.10$), 0.22$ \\
\hline Triple hop, LSI & 47 & $91.2 \pm 10.0$ & 15 & $93.5 \pm 10.8$ & $1.03(0.96$ to 1.10$), 0.44$ \\
\hline $6 \mathrm{~m}$ Timed hop, LSI & 47 & $96.1 \pm 9.9$ & 16 & $92.4 \pm 6.2$ & $0.97(0.93$ to 1.02$), 0.20$ \\
\hline KOS-ADLS & 51 & $89.2 \pm 9.6$ & 18 & $86.9 \pm 10.7$ & 0.98 (0.94 to 1.03$), 0.43$ \\
\hline Global rating scale & 51 & $86.4 \pm 13.9$ & 18 & $77.7 \pm 16.1$ & 0.98 (0.95 to 1.01$), 0.12$ \\
\hline \multicolumn{6}{|l|}{ Patients who returned before 9 months } \\
\hline Return to level I sports, months from surgery & 23 & $7.3 \pm 0.9$ & 15 & $5.7 \pm 1.7$ & $0.49(0.34$ to 0.70$),<0.001$ \\
\hline \multicolumn{6}{|l|}{ Patients who returned 9 months or later } \\
\hline Return to level I sports, months from surgery & 29 & $13.4 \pm 4.0$ & 7 & $10.4 \pm 1.0$ & 0.75 (0.49 to 1.14$), 0.18$ \\
\hline
\end{tabular}

demands on the knee, and our finding of an increased risk with earlier sports return may be specific to athletes who return to level I sports. The increased risk could be due to insufficient biological healing (eg, graft incorporation and remodelling), incomplete rehabilitation or both. Our results suggest that time to return is associated with reinjury, and the effect is larger in the early months after surgery. Of note, all patients who returned to sport before 5 months suffered a knee reinjury. Beyond 9 months after surgery, we did not find a statistically significant reduction in the risk for knee reinjury. Still, $19.4 \%$ of these patients also suffered knee reinjuries. Time alone is therefore not sufficient for determining readiness for level I sports participation.

Our findings support the use of both time-based and functional RTS criteria. There was an estimated 84\% lower knee reinjury rate in patients who passed RTS criteria, a magnitude

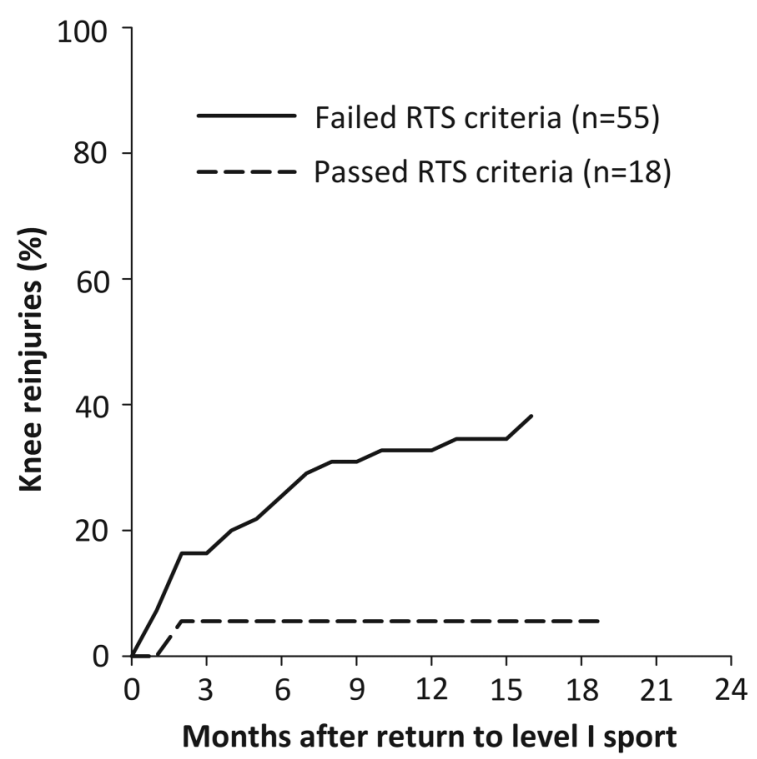

Figure 2 Knee reinjuries after return to level I sports in those who failed and those who passed return to sport (RTS) criteria prior to return. of high clinical relevance. This finding was not statistically significant $(p=0.075)$, most likely due to the low statistical power, as only one of the 18 patients who passed the criteria and returned to sport suffered a knee reinjury. The low proportion of patients who passed RTS criteria is not surprising as the investigated RTS battery was not used to determine when patients were cleared to RTS in our study. Further, patients were tested $2.3 \pm 2.4$ months prior to return, and a higher number of patients might have passed had they undergone testing immediately prior to RTS. We have previously reported similar rates of passing RTS criteria at 6 months for the entire Delaware-Oslo ACL Cohort. ${ }^{23}$ The rate of passing RTS criteria was $52.5 \%$ at 1 year after surgery, ${ }^{23}$ and only $66 \%$ had quadriceps strength symmetry $\geq 90 \% 2$ years after surgery. ${ }^{5}$ These outcomes exist in a cohort that has shown superior patient-reported outcomes compared with the general ACL reconstructed population, ${ }^{32}$ suggesting that even larger functional deficits might persist after usual care.

While we still do not know the optimal content of an RTS test battery, ${ }^{19}$ our results show that quadriceps strength testing should be included. Asymmetrical quadriceps strength at the time of RTS is associated with asymmetrical knee biomechanics during hopping, ${ }^{33}$ which in turn has been found to predict a second ACL injury. ${ }^{34}$ Quadriceps weakness is also a risk factor for knee OA, ${ }^{35}$ further highlighting the importance of thorough rehabilitation and quadriceps strength assessment. Postural control deficits and altered neuromuscular control of the hip and knee have also been found to predispose an athlete to a second ACL injury. ${ }^{34}$ So far, modifiable risk factors for reinjury after ACL reconstruction have only been identified using sophisticated testing equipment (isokinetic dynamometry and 3dimensional motion analysis), and a future focus should be to validate more clinically accessible tests.

The main strength of this study is the frequent follow-up and high follow-up rate of ACL reconstructed patients who were consecutively screened for inclusion at one sports medicine clinic. A main limitation is the lack of exact athlete exposure time. RTS was defined as their first participation in a level I sport, and not necessarily full participation including match play. We were unable to control for the exact time spent in sports, full or limited participation, and training/match exposure. 


\section{CONCLUSION}

Athletes who undergo ACL reconstruction should be informed that postoperative participation in level I sports increases the 2-year knee reinjury rate more than four times. A later return to level I sports and more symmetrical quadriceps strength prior to return decreases this rate significantly. A combination of strict time-based and functional RTS criteria therefore has great potential to improve long-term function, substantially decrease the prevalence of post-traumatic knee OA in these patients, and reduce downstream healthcare costs.

\section{What are the findings?}

- In the first 2 years after $A C L$ reconstruction, $30 \%$ of people who returned to level I sports sustained a reinjury compared with $8 \%$ of those who participated in lower level sports.

- For every month that return to sport was delayed, until 9 months after $A C L$ reconstruction, the rate of knee reinjury was reduced by $51 \%$.

- More symmetrical quadriceps strength prior to return to sport significantly reduced the knee reinjury rate.

\section{How might it impact on clinical practice in the future?}

- Clinicians should inform patients of the increased risk of knee reinjury if they decide to return to level I sport.

- Strict time-based and functional return to sport criteria should be implemented.

- Return to level I sport should be delayed until at least 9 months have passed from surgery and the patient has regained quadriceps strength comparable to the uninjured side.

\section{Twitter Follow Håvard Moksnes at @HMoksnes}

Acknowledgements The authors thank Ingrid Eitzen, Annika Storevold, Ida Svege, Espen Selboskar, Karin Rydevik and Marte Lund for their assistance in data collection for this study. They acknowledge the Norwegian Sports Medicine Clinic, NIMI (http://www.nimi.no), for supporting the Norwegian Research Center for Active Rehabilitation (NAR; http://www.active-rehab.no) with rehabilitation facilities and research staff.

Contributors All authors contributed to the conception and design of the study. HG and HM were responsible for data collection. HG performed the data analysis and all the authors contributed to the interpretation. HG drafted the manuscript and all the authors revised it critically and gave their approval of the final version.

Funding National Institutes of Health (R37 HD037985).

Competing interests None declared.

Ethics approval South Eastern Norway Regional Committee for Medical Research Ethics.

Provenance and peer review Not commissioned; externally peer reviewed.

\section{REFERENCES}

1 Griffin LY, Albohm MJ, Arendt EA, et al. Understanding and preventing noncontact anterior cruciate ligament injuries: a review of the Hunt Valley II meeting, January 2005. Am J Sports Med 2006;34:1512-32.

2 Paterno MV, Rauh MJ, Schmitt LC, et al. Incidence of contralateral and ipsilateral anterior cruciate ligament $(\mathrm{ACL})$ injury after primary $\mathrm{ACL}$ reconstruction and return to sport. Clin J Sport Med 2012;22:116-21.
3 Paterno MV, Rauh MJ, Schmitt LC, et al. Incidence of second ACL injuries 2 years after primary $\mathrm{ACL}$ reconstruction and return to sport. Am J Sports Med 2014;42:1567-73.

4 Øiestad BE, Engebretsen L, Storheim K, et al. Knee osteoarthritis after anterior cruciate ligament injury: a systematic review. Am J Sports Med 2009;37:1434-43.

5 Grindem H, Eitzen I, Engebretsen L, et al. Nonsurgical or surgical treatment of ACL injuries: knee function, sports participation, and knee reinjury: the Delaware-Oslo ACL Cohort Study. J Bone Joint Surg Am 2014;96:1233-41.

6 Webster $\mathrm{KE}$, Feller JA, Leigh WB, et al. Younger patients are at increased risk for graft rupture and contralateral injury after anterior cruciate ligament reconstruction. Am J Sports Med 2014;42:641-7.

7 Filbay SR, Ackerman IN, Russell TG, et al. Health-related quality of life after anterior cruciate ligament reconstruction: a systematic review. Am J Sports Med 2014;42:1247-55.

8 Frobell RB, Roos HP, Roos EM, et al. Treatment for acute anterior cruciate ligament tear: five year outcome of randomised trial. BMJ 2013;346:f232.

9 Mather RC 3rd, Koenig L, Kocher MS, et al. Societal and economic impact of anterior cruciate ligament tears. J Bone Joint Surg Am 2013;95:1751-9.

10 Hefti F, Müller W, Jakob RP, et al. Evaluation of knee ligament injuries with the IKDC form. Knee Surg Sports Traumatol Arthrosc 1993;1:226-34.

11 Grindem H, Eitzen I, Snyder-Mackler L, et al. Online registration of monthly sports participation after anterior cruciate ligament injury: a reliability and validity study. Br J Sports Med 2014;48:748-53.

12 Moksnes H, Snyder-Mackler L, Risberg MA. Individuals with an anterior cruciate ligament-deficient knee classified as noncopers may be candidates for nonsurgical rehabilitation. J Orthop Sports Phys Ther 2008;38:586-95.

13 Kaeding CC, Pedroza AD, Reinke EK, et al. Risk factors and predictors of subsequent $A C L$ injury in either knee after $A C L$ reconstruction: prospective analysis of 2488 primary $\mathrm{ACL}$ reconstructions from the MOON cohort. Am J Sports Med 2015:43:1583-90.

14 Myklebust G, Holm I, Maehlum S, et al. Clinical, functional, and radiologic outcome in team handball players 6 to 11 years after anterior cruciate ligament injury: a follow-up study. Am J Sports Med 2003;31:981-9.

15 Salmon L, Russell V, Musgrove T, et al. Incidence and risk factors for graft rupture and contralateral rupture after anterior cruciate ligament reconstruction. Arthroscopy 2005;21:948-57.

16 Shelbourne KD, Gray T, Haro M. Incidence of subsequent injury to either knee within 5 years after anterior cruciate ligament reconstruction with patellar tendon autograft. Am J Sports Med 2009;37:246-51.

17 Swärd P, Kostogiannis I, Roos H. Risk factors for a contralateral anterior cruciate ligament injury. Knee Surg Sports Traumatol Arthrosc 2010;18:277-91.

18 Thomeé $\mathrm{R}$, Kaplan Y, Kvist J, et al. Muscle strength and hop performance criteria prior to return to sports after $A C L$ reconstruction. Knee Surg Sports Traumatol Arthrosc 2011;19:1798-805.

19 Barber-Westin SD, Noyes FR. Factors used to determine return to unrestricted sports activities after anterior cruciate ligament reconstruction. Arthroscopy 2011;27:1697-705

20 Spindler KP, Wright RW. Clinical practice. Anterior cruciate ligament tear. N Engl J Med 2008;359:2135-42

21 Daniel DM, Stone ML, Sachs $\mathrm{R}$, et al. Instrumented measurement of anterior knee laxity in patients with acute anterior cruciate ligament disruption. Am J Sports Med 1985; 13:401-7.

22 Eitzen I, Moksnes H, Snyder-Mackler L, et al. A progressive 5-week exercise therapy program leads to significant improvement in knee function early after anterior cruciate ligament injury. J Orthop Sports Phys Ther 2010:40:705-21.

23 Logerstedt D, Di Stasi S, Grindem H, et al. Self-reported knee function can identify athletes who fail return-to-activity criteria up to 1 year after anterior cruciate ligament reconstruction: a Delaware-Oslo ACL Cohort Study. J Orthop Sports Phys Ther 2014:44:914-23.

24 Hartigan EH, Axe MJ, Snyder-Mackler L. Time line for noncopers to pass return-to-sports criteria after anterior cruciate ligament reconstruction. J Orthop Sports Phys Ther 2010;40:141-54.

25 Logerstedt D, Grindem H, Lynch A, et al. Single-legged hop tests as predictors of self-reported knee function after anterior cruciate ligament reconstruction: the Delaware-Oslo ACL Cohort Study. Am J Sports Med 2012;40:2348-56.

26 Grindem H, Logerstedt D, Eitzen I, et al. Single-legged hop tests as predictors of self-reported knee function in nonoperatively treated individuals with anterior cruciate ligament injury. Am J Sports Med 2011;39:2347-54.

27 Irrgang JJ, Snyder-Mackler L, Wainner RS, et al. Development of a patient-reported measure of function of the knee. J Bone Joint Surg Am 1998:80:1132-45.

28 van Meer BL, Meuffels DE, van Eijsden WA, et al. Which determinants predict tibiofemoral and patellofemoral osteoarthritis after anterior cruciate ligament injury? A systematic review. Br J Sports Med 2015:49:975-83.

29 Granan LP, Forssblad M, Lind M, et al. The Scandinavian ACL registries 20042007: baseline epidemiology. Acta Orthop 2009;80:563-7.

30 Frobell RB, Roos EM, Roos HP, et al. A randomized trial of treatment for acute anterior cruciate ligament tears. N Engl J Med 2010;363:331-42. 


\section{Original article}

31 Laboute E, Savalli L, Puig P, et al. Analysis of return to competition and repeat rupture for 298 anterior cruciate ligament reconstructions with patellar or hamstring tendon autograft in sportspeople. Ann Phys Rehabil Med 2010;53:598-614.

32 Grindem H, Granan LP, Risberg MA, et al. How does a combined preoperative and postoperative rehabilitation programme influence the outcome of $\mathrm{ACL}$ reconstruction 2 years after surgery? A comparison between patients in the Delaware-Oslo ACL Cohort and the Norwegian National Knee Ligament Registry. Br J Sports Med 2015;49:385-9.
33 Palmieri-Smith RM, Lepley LK. Quadriceps strength asymmetry after anterior cruciate ligament reconstruction alters knee joint biomechanics and functional performance at time of return to activity. Am J Sports Med 2015;43:1662-9.

34 Paterno MV, Schmitt LC, Ford KR, et al. Biomechanical measures during landing and postural stability predict second anterior cruciate ligament injury after anterior cruciate ligament reconstruction and return to sport. Am I Sports Med 2010;38:1968-78.

35 Øiestad BE, Juhl CB, Eitzen I, et al. Knee extensor muscle weakness is a risk factor for development of knee osteoarthritis. A systematic review and meta-analysis. Osteoarthritis Cartilage 2015;23:171-7. 